\title{
Gene mutations in the D-loop region of mitochondrial DNA in oral squamous cell carcinoma
}

\author{
RONG-TAO YUAN, YANG SUN, LING-XUE BU and MU-YUN JIA \\ Department of Oral and Maxillofacial Surgery, \\ The Affiliated Hospital of Qingdao University, Qingdao, Shandong 266003, P.R. China
}

Received March 23, 2014; Accepted December 19, 2014

DOI: $10.3892 / \mathrm{mmr} .2015 .3240$

\begin{abstract}
The present study aimed to investigate gene mutations in the displacement-loop (D-loop) region of mitochondrial DNA (mtDNA) in patients with oral squamous cell carcinoma (OSCC) in order to examine the role of gene mutation in mtDNA in OSCC tumorigenesis. mtDNA was obtained from cancer tissues, paracancerous tissues and normal mucosal tissues of thirty patients with OSCC. The D-loop region of the mtDNA was amplified using polymerase chain reaction, sequenced and then analyzed by Chromas software and BLAST to identify the mutation sites. Mutations in the D-loop region were observed in the cancer tissue samples of eight out of thirty cases with OSCC, with a mutation rate of $27 \%$. There were nine mutations in total, including one point mutation, two base deletions, three insertion mutations and three heterozygous mutations. In these mutations, base deletions were different from each other and heterozygous mutations did not have the same mutation form; however, the three insertion mutations were the same, consisting of an insertion of a $\mathrm{C}$ base. One case contained a T/A heterozygous mutation as well as base insertion of $\mathrm{C}$. The eight cases with mutations in the D-loop region consisted of three cases of tongue cancer, two cases of soft palate cancer, one case of floor of the mouth cancer, one case of oropharyngeal cancer and one case of lip cancer. This study demonstrated mutations in the mtDNA D-loop region in OSCC cells; however, the association between occurrences of OSCC and mtDNA mutations requires further investigation.
\end{abstract}

\section{Introduction}

Oral squamous cell carcinoma (OSCC) is the most common malignancy of the oral and maxillofacial region, and the sixth most common type of tumor worldwide (1). Although surgical treatment, radiotherapy and chemotherapy have been regarded

Correspondence to: Dr Rong-Tao Yuan, Department of Oral and Maxillofacial Surgery, The Affiliated Hospital of Qingdao University, 16 Jiangsu Road, Qingdao, Shandong 266003, P.R. China E-mail: yrtao_66@163.com

Key words: oral squamous cell carcinoma, mitochondrial DNA, mutation as mature technologies, the prognosis of patients with OSCC remains poor and the overall 5-year survival rates have remained at $50 \%$ (2). Therefore, further investigation into the pathogenesis of OSCC continues to be important.

The majority of human cancer types are characterized by genetic instabilities. Mitochondrial DNA (mtDNA) is the only genetic material of the human genome, with the exception of nuclear DNA (3-5). mtDNA somatic mutations have been increasingly observed in human cancer, such as stomach, liver and lung cancer (6-8), and have been proposed as important oncological biomarkers. However, the biological significance of mtDNA mutations in OSCC remains to be elucidated. The displacement-loop (D-loop) region, the only non-coding region in mtDNA, is considered to be important as it is the major control site for mtDNA expression and it is also involved in mtDNA replication. Mutations occur throughout the mitochondrial genome in tumors, but are most frequently detected in the D-loop region $(6,7)$.

In the present study, gene mutations in the D-loop region of mtDNA were investigated in thirty patients with OSCC in order to examine the role of gene mutations of mtDNA in OSCC tumorigenesis.

\section{Materials and methods}

Patients and samples. Tumor samples were obtained from resected specimens of 30 patients with primary OSCC in the Department of Oral and Maxillofacial Surgery, Affiliated Hospital Medical College Qingdao University (Qingdao, China) between March, 2009 and June, 2010. The study was approved by the ethics committee of the Affiliated Hospital of Qingdao University (Qingdao, China). Written informed consent was obtained from all patients or their families. Fresh cancer tissues, paracancerous tissues and normal mucosal tissues from the same patient were obtained and immediately put into $1.5 \mathrm{ml}$ frozen pipes for preservation in $-196^{\circ} \mathrm{C}$ liquid nitrogen. The patients consisted of 21 males and nine females, and ranged in age between 29 and 72 years old (mean age, 56.5 years). The tumor sites included 11 tongue cancers, six gingival cancers, four floor of the mouth cancers, four soft palate cancers, two buccal mucosa cancers, two oropharyngeal cancers and one lip cancer.

Extraction of mtDNA. A total of $30 \mathrm{mg}$ tissue of the sample was extracted as required and ground into a fine powder, 
Table I. Sequences of primers.

\begin{tabular}{ll}
\hline Primer & \multicolumn{1}{c}{ Sequence } \\
\hline P1 & 5'-TGATGTGAGCCCGTCTAAAC-3' \\
P2 & 5'-GAATCGGAGGACAACCAGTA-3' \\
P3 & 5'-TATCCCGCACAAGAGTGCTACTC-3' \\
P4 & 5'-CTCCAGCGTCTCGCAATGCTA-3'
\end{tabular}

Table II. Mutations in the displacement-loop region of mitochondrial DNA in oral squamous cell carcinoma.

\begin{tabular}{|c|c|c|c|c|c|c|c|}
\hline $\begin{array}{l}\text { Sample } \\
\text { no. }\end{array}$ & Age & Gender & Pathology & $\begin{array}{l}\text { Mutation } \\
\text { site }\end{array}$ & $\begin{array}{c}\text { Seq. } \\
\text { normal }\end{array}$ & $\begin{array}{c}\text { Seq. } \\
\text { adjacent }\end{array}$ & $\begin{array}{l}\text { Sequence of } \\
\text { cancer tissue }\end{array}$ \\
\hline 1 & 57 & Male & Well-differentiated SCC & 249 & A & A & Deletion mutants A \\
\hline 2 & 67 & Male & $\begin{array}{l}\text { Moderately-differentiated } \\
\text { SCC }\end{array}$ & 16289 & $\mathrm{~T}$ & $\mathrm{~T}$ & Replacement mutation $\mathrm{C}$ \\
\hline 3 & 29 & Female & Well-differentiated SCC & 519 & $\mathrm{~T}, \mathrm{G}$ & $\mathrm{T}, \mathrm{G}$ & Deletion mutants T,G \\
\hline 4 & 72 & Male & Well-differentiated SCC & 313 & None & None & Insertional mutagenesis $\mathrm{C}$ \\
\hline 5 & 67 & Male & $\begin{array}{l}\text { Moderately-differentiated } \\
\text { SCC }\end{array}$ & 16088 & $\mathrm{G}$ & $\mathrm{G}$ & Heterozygous mutation $\mathrm{G}, \mathrm{A}$ \\
\hline 6 & 61 & Male & $\begin{array}{l}\text { Moderately-differentiated } \\
\text { SCC }\end{array}$ & 313 & None & None & Insertional mutagenesis $\mathrm{C}$ \\
\hline 7 & 55 & Male & Well-differentiated SCC & 16263 & $\mathrm{C}$ & $\mathrm{C}$ & Heterozygous mutation $\mathrm{C}, \mathrm{T}$ \\
\hline 8 & 31 & Male & Well-differentiated SCC & $\begin{array}{c}313 \\
16522\end{array}$ & None $\mathrm{T}$ & None $\mathrm{T}$ & $\begin{array}{l}\text { Insertional mutagenesis C, } \\
\text { Heterozygous mutation T,A }\end{array}$ \\
\hline
\end{tabular}

SCC, squamous cell carcinoma; Seq. normal, sequence in normal tissue; Seq. adjacent, sequence in adjacent tissue.

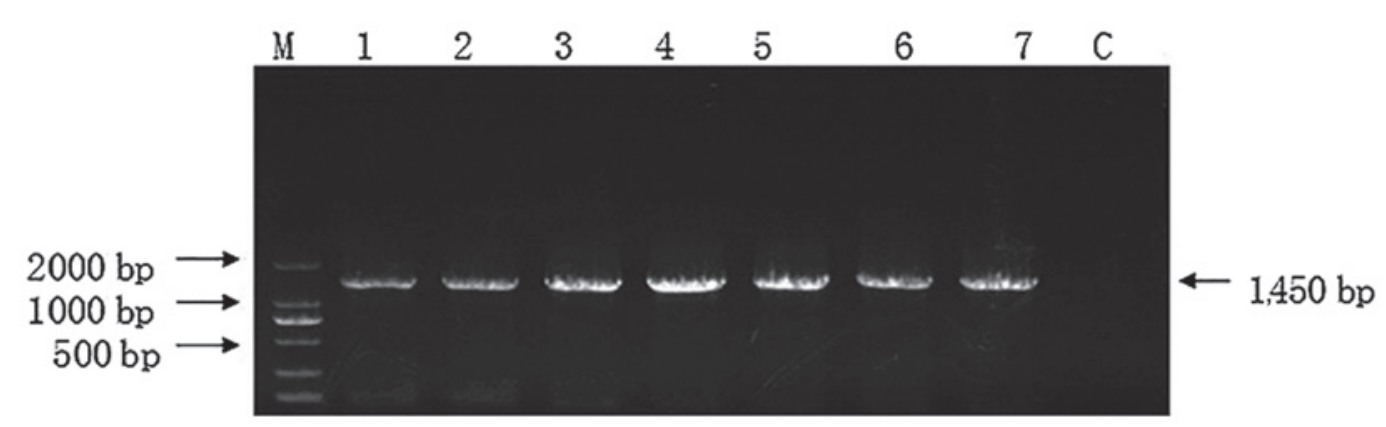

Figure 1. Results of electrophoresis of the mitochondrial DNA polymerase chain reaction product of a random selection of patient cases. Lanes: M: marker;1-7: samples; C: negative control.

then mtDNA was extracted using an mtDNA extraction kit (Shanghai Genmed Pharmaceutical Scientific Company, Shanghai, China). The purity and content of the mtDNA were measured using an ultra trace spectrophotometer (NanoDrop ND-2000C; Thermo Fisher Scientific, Waltham, MA, USA). The value required was A280/A260>1.80, which meant $20 \mu \mathrm{l}$ $(2 \mathrm{ng} / \mu \mathrm{l})$ mtDNA was obtained.

Polymerase chain reaction (PCR) amplification. The PCR amplification primer sequences were as follows: P1, 5'-TGATGTGAGCCCGTCTAAAC-3'; P2, 5'-GAA TCGGAGGACAACCAGTA-3'; P3: 5'-TATCCCGCACAAGAGTGCTACTC-3' and P4:
5'-CTCCAGCGTCTCGCAATGCTA-3' which resulted in an amplification product of 1,450 bp, including the D-loop region. Amplification was accomplished with a $50 \mu \mathrm{l}$ PCR reaction using $25 \mu \mathrm{l}$ of Power Taq PCR MasterMix polymerase (DR100A; Takara Bio, Inc., Otsu, Japan) and $3 \mu$ l template DNA (including $15 \mu \mathrm{l}$ of upstream and $1.5 \mu \mathrm{l}$ of downstream primers supplied by Shanghai Sangon Biological Engineering Co., Ltd, Shanghai, China). The PCR conditions were as follows: $94^{\circ} \mathrm{C}$ for $5 \mathrm{~min}, 35$ cycles of $94^{\circ} \mathrm{C}$ for $1 \mathrm{~min}, 55^{\circ} \mathrm{C}$ for $1 \mathrm{~min}, 72^{\circ} \mathrm{C}$ for $2 \mathrm{~min}$ and then an extension step at $72^{\circ} \mathrm{C}$ for $7 \mathrm{~min}$ followed by holding at $4^{\circ} \mathrm{C}$. The specificity of the reactions was confirmed using agarose gel electrophoresis. The concentration of each purified PCR product was measured using a Tanon 2500 gel 


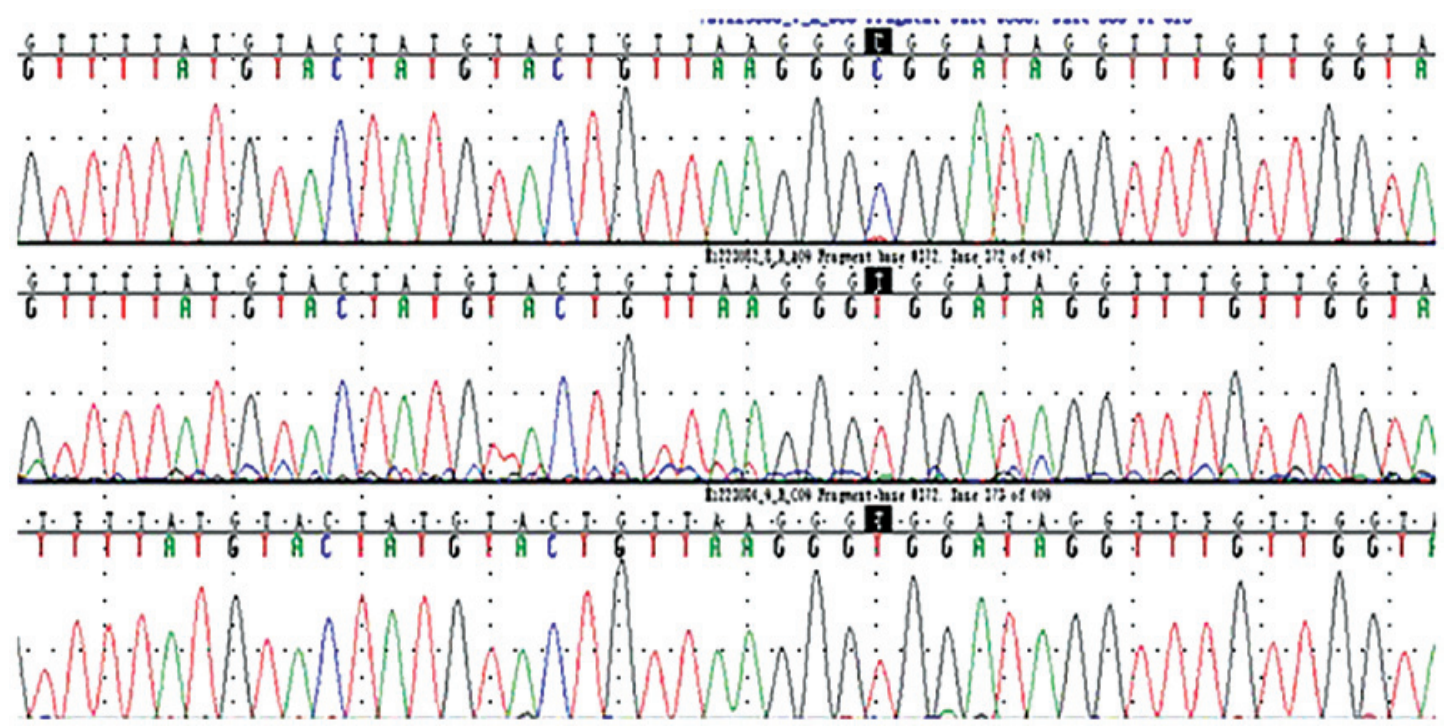

Figure 2. Sequencing results revealed clear peaks. Black marker indicates mutations in the cancer tissues, compared with paracancerous tissue and normal tissue.

\begin{tabular}{|c|c|c|c|}
\hline \multicolumn{3}{|c|}{$\begin{array}{l}>\text { lel } \mid 58953 \\
\text { Length }=1239\end{array}$} & $\begin{array}{l}\text { Sort alignments for thi } \\
\text { E value Score Perce } \\
\text { Query start position }\end{array}$ \\
\hline $\begin{array}{l}\text { Score } \\
\text { Ident } \\
\text { Stran }\end{array}$ & $\begin{array}{l}=11 \\
=\text { ies } \\
=\text { plu }\end{array}$ & $\begin{array}{l}7 \text { bits }(637), \text { Expect }=0.0 \\
=677 / 695 \text { (978), Gaps }=7 / 695 \quad(18) \\
/ \text { plus }\end{array}$ & \\
\hline Query & 1 & 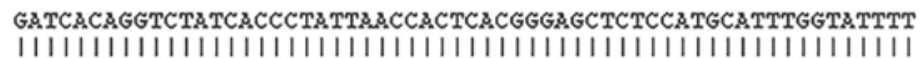 & 60 \\
\hline Sbjet & 547 & GATCACAGGTCTATCACCCTATTAACCACTCACGGGAGCTCTCCATGCATTTGGTATTTT & 606 \\
\hline Query & 61 & 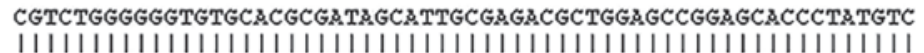 & 120 \\
\hline Sbjet & 607 & CGTCTGGGGGGTGTGCACGCGATAGCATTGCGAGACGCTGGAGCCGGAGCACCCTATGTC & 666 \\
\hline Query & 121 & & 179 \\
\hline Sbjet & 667 & GCAGTATCTGTCTTTGATTCCTGCCCCAT-CCTATTATTTATCGCACCTACGTTCAATAT & 725 \\
\hline Query & 180 & TACAGGCGAGCATACTTACTGAAGTGTGTTAATTAATTAATGCTTGTAGGACATAATAAT & 239 \\
\hline & & & \\
\hline Sbjet & 726 & TACAGGCGAACATACTTACCAAAGTGTGTTARTAATTAATGCTTGTAGGACATAATART & 785 \\
\hline Query & 240 & AACGACTAAATGTCTGCACAGCTGCTTTCCACACAGACATCATAACA_AAAAATTTCACC & 299 \\
\hline Sbjet & 786 & AACAATTGATGTCTGCACAGCCGCTTTCCACACAGACATCATAACAAAAAATTCCACC & 845 \\
\hline Query & 300 & AaAcceccec-tccecC-GCTTCTGGCCACAGCACTTAAACACATCTCTGCCAAACCCCA & 357 \\
\hline Sbjet & 846 & AAACCCCCCCCTCCCCCCGCTTCTGGCCACAGCACTTAAACACATCTCTGCCAAACCCCA & 905 \\
\hline Query & 358 & AAAACAAAGACCCTAACACCAGCCTAACCAGATTTCAAATTTTATCTTTTGGCGTATA & 417 \\
\hline Sbjet & 906 & AAA.ACA_AGA_CCCTA.ACACCAGCCTAACCAGATTTCAAATTTTATCTTTTGGCGGTATG & 965 \\
\hline Quex & 418 & CACTTTTAACAGTCACCCCCTAACTAACACATTATTTTCCCCTCCCACTCCCATACTACT & 477 \\
\hline Sbjet & 966 & САСTTTTAACAGTCACCCCCСAACTAACACATTATTTTCCCCTCCCACTCCСATACTACT & 1025 \\
\hline
\end{tabular}

Figure 3. BLAST was used to compare the sequencing results with the Cambridge sequence in GenBank. There were multiple single nucleotide polymorphisms in each case of oral squamous cell carcinoma.

imaging analysis system (Tanon Science and Technology Co., Ltd., Shanghai, China).

Gene sequencing and analysis. All PCR products were purified and sequenced by Shanghai Maipu Biotechnology Company according to the manufacturer's instructions. There were four primers as shown in Table I. Chromas software (2.3.0.0; Technelysium, Brisbane, Australia) and BLAST (http://blast. ncbi.nlm.nih.gov/Blast.cgi) were used to analyze the sequencing and to search mutations. The sequences of D-loop region mtDNA in the present study were compared with the Cambridge Standard sequence in GenBank (http://www.ncbi.nlm.nih.gov/ genbank/). If the sequences in normal tissue, adjacent tissue and cancer tissue were the identical, but differed to the Cambridge Standard sequence provided in GenBank, they were identified as single nucleotide polymorphisms. Mutations were identified if the sequence in normal tissue was identical to that of adjacent tissue, but differed to that of cancer tissue. 
Statistical analysis. Statistical analysis using the $\chi^{2}$ test and identification of significant mutations were performed using SPSS 16.0 software (SPSS, Inc., Chicago, IL, USA).

\section{Results}

PCR amplification and sequencing. All PCR amplification products of the thirty cases with OSCC exhibited a 1,450-bp fragment of the mtDNA D-loop region, (Fig. 1). The sequencing results demonstrated clear peaks (Fig. 2). The first line presents the cancer tissue sequence, the second presents the adjacent tissue sequence and the third presents normal tissue. Black markers indicate the mutation in cancer tissue, which was identified as blue peak $\mathrm{C}$ differed to red peak $\mathrm{T}$ at the same position in the adjacent and normal tissues.

Analysis of sequencing. There were multiple single nucleotides polymorphisms in each case of OSCC when compared with the mtDNA Cambridge sequence in GenBank (http://www. ncbi.nlm.nih.gov/genbank/) as shown in Fig. 3. Mutations in the D-loop region were identified in the cancer tissue samples of $8 / 30$ cases with OSCC, with a mutation rate of $27 \%$. There were nine mutations in total, including one point mutation, two base deletions, three insertion mutations and three heterozygous mutations. In these mutations, base deletions were different from each other and heterozygous mutations did not have the same mutation form; however, the three insertion mutations were the same, consisting of an insertion of a $\mathrm{C}$ base. One case contained a T/A heterozygous mutation as well as a base insertion of $\mathrm{C}$ (Table II).

Clinical significance. The eight cases with a mutation in the D-loop region consisted of three tongue cancers, two soft palate cancers, one floor of the mouth cancer, one oropharyngeal cancer and one lip cancer.

\section{Discussion}

mtDNA is the only genetic material of the human genome not contained in the nucleus. It is present in a closed double-stranded state, with a total length of $16,569 \mathrm{bp}$, containing 37 genes, including the structural genes encoding the thirteen protein subunits, 12S rRNA, 16S rRNA and $2 S$ tRNA, that make up the oxidative phosphorylation system. The D-loop region, the only non-coding region in mtDNA, is located at basepairs 1,602-577, accounting for $6 \%$ of the total mtDNA. The D-loop region is the major control site in the regulation of mtDNA transcription and is also involved in mtDNA replication (3-5). In recent years, somatic mutations in the mtDNA have been increasingly observed in human cancers, such as stomach (6), liver (7), lung (8), ovarian (9), breast (10) and pancreatic cancer (11). Mutations occur throughout the mitochondrial genome in tumors, but are most frequently detected in the D-loop region. At present, studies investigating the mtDNA mutations in head and neck tumors remain rare.

In our previous small sample study, it was demonstrated that there were mutation sites in the D-loop region of mtDNA in three out of seven OSCC cases and numerous single nucleotide polymorphisms in the D-loop region in all cases. In the present study, a larger sample study, the D-loop region of mtDNA in thirty patients with OSCC was screened and the rate of gene mutation in the D-loop region was $27 \%$, which was similar to other studies in which the mutation rates in human cancers were $20-78 \%$ (12-14).

Excluding single nucleotide polymorphisms, nine mutation sites were found in the D-loop region of mtDNA in the present study and insertional mutagenesis $\mathrm{C}$ at site 313 was also observed, which was similar to that identified in liver cancer and colorectal cancer (13-14). Site 313 mutations may affect the regulation of mtDNA transcription and may be an important area of mtDNA investigation in the future.

Bragoszewski et al (15) investigated mtDNA in ovarian cancer and identified heterozygous mutations, such as $\mathrm{C} / \mathrm{T}$ replacement at site 16,193 and site 16,218 and G/A replacement at site 16,391, which were seldom reported in the literature. In the present study, there were similar mutations in the D-loop region of mtDNA which, as a regulatory area, may be able to reduce mtDNA replication and ND6 transcription. It was hypothesized that these heterozygous mutations were rare mutation sites and require further investigation.

Certain gene mutation sites in mtDNA, which are closely associated with tumorigenesis and progression, have already been identified (16). However, the functional significance of mutations in the D-loop region of mtDNA and its role in tumorigenesis remain to be elucidated and require further investigation at the protein level and in larger samples. These mutations may in the future provide novel markers for early clinical diagnosis and novel targets for chemotherapy.

\section{Acknowledgements}

The present study was supported by a grant from Shanghai Science and Technology Committee (grant nos. 08DZ2271100 and S30206-kf13).

\section{References}

1. Ng SH, Yen TC, Liao CT, Chang JT, Chan SC, Ko SF, Wang HM and Wong HF: 18F-FDG PET and CT/MRI in oral cavity squamous cell carcinoma: a prospective study of 124 patients with histologic correlation. J Nucl Med 46: 1136-1143, 2005.

2. Parkin DM, Bray F, Ferlay J and Pisani P: Global cancer statistics, 2002. CA Cancer J Clin 55: 74-108, 2005.

3. Penta JS, Johnson FM, Wachsman JT and Copeland WC: Mitochondrial DNA in human malignancy. Mutat Res 488: 119-133, 2001.

4. McFarland R, Taylor RW and Turnbull DM: Mitochondrial disease - its impact, etiology and pathology. Curr Top Dev Biol 77: 113-155, 2007.

5. Stewart JB, Freyer C, Elson JL and Larsson NG: Purifying selection of mtDNA and its implications for understanding evolution and mitochondrial disease. Nat Rev Genet 9: 657-662, 2008

6. Hung WY, Wu CW, Yin PH, Chang CJ, Li AF, Chi CW, Wei YH and Lee HC: Somatic mutations in mitochondrial genome and their potential roles in the progression of human gastric cancer. Biochim Biophys Acta 1800: 264-270, 2010.

7. Wang C, Zhang F, Fan H, Peng L, Zhang R, Liu S and Guo Z: Sequence polymorphisms of mitochondrial D-loop and hepatocellular carcinoma outcome. Biochem Biophys Res Commun 406: 493-496, 2011.

8. Ding C, Li R, Wang P, Jin P, Li S and Guo Z: Identification of sequence polymorphisms in the D-loop region of mitochondrial DNA as a risk factor for lung cancer. Mitochondrial DNA 23: 251-254, 2012. 
9. Guerra F, Kurelac I, Magini P, Cormio A, Santini D, Ceccarelli C and Gasparre G: Mitochondrial DNA genotyping reveals synchronous nature of simultaneously detected endometrial and ovarian cancers. Gynecol Oncol 122: 457-458, 2011.

10. Cai FF, Kohler C, Zhang B, Chen WJ, Barekati Z, Garritsen HS Lenner P, Toniolo P, Zhang JJ and Zhong XY: Mutations of mitochondrial DNA as potential biomarkers in breast cancer. Anticancer Res 31: 4267-4271, 2011.

11. Lam ET, Bracci PM, Holly EA, Chu C, Poon A, Wan E, White K, Kwok PY, Pawlikowska L and Tranah GJ: Mitochondrial DNA sequence variation and risk of pancreatic cancer. Cancer Res 72: 686-695, 2012

12. Czarnecka AM, Gammazza AM, Di Felice V, Zummo G and Cappello F: Cancer as a 'Mitochondriopathy'. J Cancer Mol 3: 71-79, 2007.

13. Wong LJ, Tan DJ, Bai RK, Yehbackground KT and Chang J: Molecular alterations in mitochondrial DNA of hepatocellular carcinomas: is there a correlation with clinicopathological profile? J Med Genet 41: e65, 2004.
14. Boland CR, Thibodeau SN, Hamilton SR, Sidransky D, Eshleman JR, Burt RW, Meltzer SJ, Rodriguez-Bigas MA, Fodde R Ranzani GN and Srivastava S: A national cancer institute workshop on microsatellite instability for cancer detection and familial predisposition: development of international criteria for the determination of microsatellite instability in colorectal cancer. Cancer Res 58: 5248-5257, 1998.

15. Bragoszewski P, Kupryjanczyk J, Bartnik E, Rachinger A and Ostrowski J: Limited clinical relevance of mitochondrial DNA mutation and gene expression analyses in ovarian cancer. BMC Cancer 8: 292, 2008.

16. Brandon M, Baldi P and Wallace DC: Mitochondrial mutations in cancer. Oncogene 25: 4647-4662, 2006. 